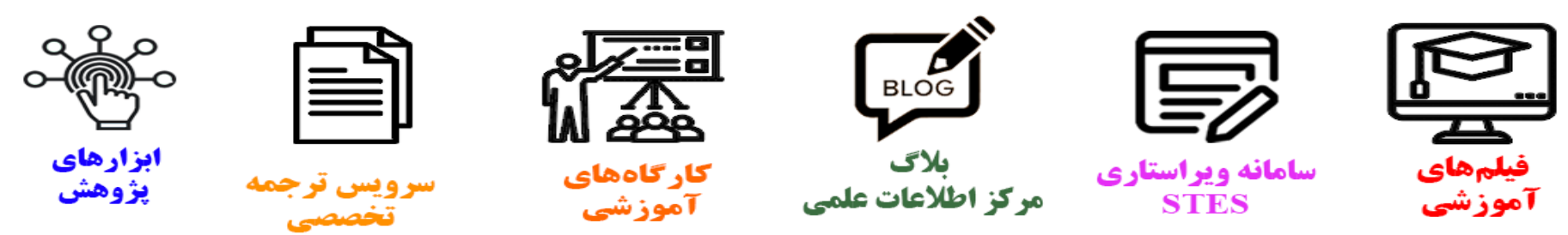

\title{
(c)
}

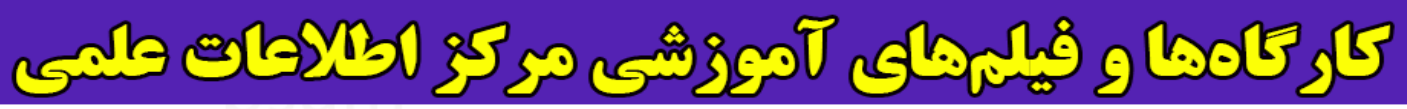
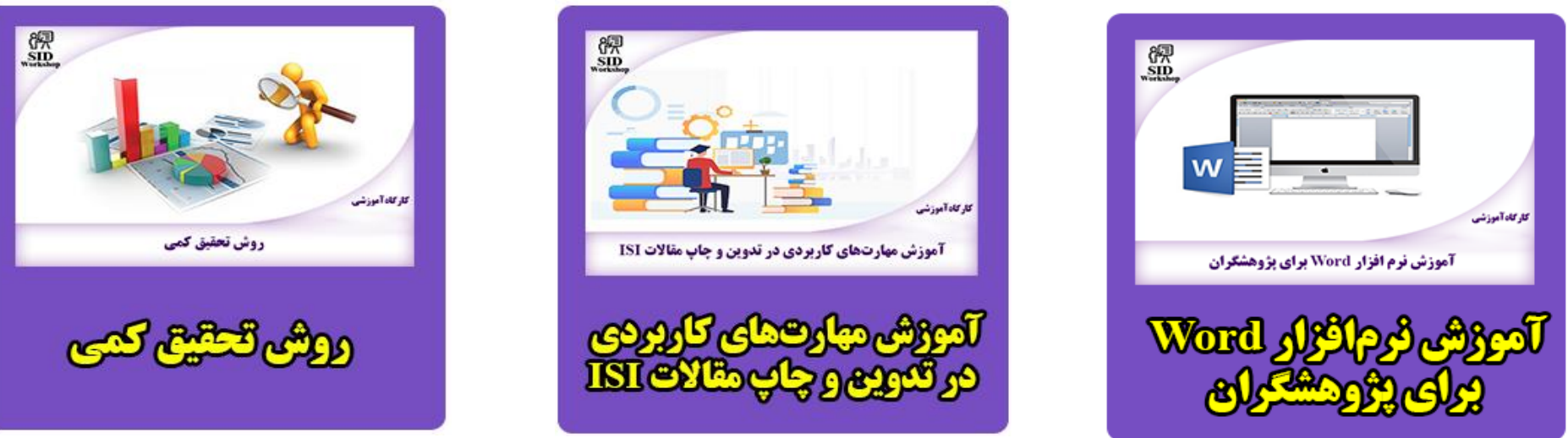


\title{
International Journal of Engineering
}

Journal Homepage: w w w. ije.ir

\section{Non-linear Behavior of New (FSFN) Moment Resisting Connections in Comparison to the Existing KBB Connections in Steel Frames}

\author{
F. Shahidi*a, F. Nateghi-Alahib, F. Shahidic \\ ${ }^{a}$ Department of Civil Engineering and Surveying, Islamic Azad University of Qazvin, Qazvin, Iran \\ ${ }^{b}$ International Institute of Earthquake Engineering and Seismology of Tehran, Tehran, Iran \\ ${ }^{c}$ Department of Civil Engineering, Islamic Azad University of Takestan, Qazvin, Iran
}

\section{PAPER INFO}

Paper history:

Received 22 January 2013

Received in revised form 17 April 2013

Accepted 16 May 2013

Keywords:

FSFN Brackets

Non-linear Numerical Analysis

Standard Load History

Near-fault Load History

KBB Brackets

\section{$\begin{array}{lllllllll}A & B & S & T & R & A & C & T\end{array}$}

After Northridge and Kobe earthquakes, several studies have been conducted to improve the seismic performance of steel structures. In this investigation, new steel moment-resisting connections (FSFN) developed by the authors were studied by the non-linear numerical analysis. These connections were single-sided beam-to-column assemblies that are representative of exterior beam-to-column connections. Seismic performance of FSFN connections in comparison to the W-series of existing KBB connections under standard and near fault load history based on AISC 341 and FEMA 355D were also studied. For this purpose, 32 analytical modeled specimens were evaluated and the results were compared. Results showed that FSFN bracket connection has a seismic performance similar to KBB connection and it is an appropriate connection for the special moment resisting frames both in far and near fault zones. More so, these brackets have smaller dimensions as compared with Kaiser Connections, they can support deeper beams up to $100 \mathrm{~cm}$. Therefore, they can be considered as an appropriate alternative for the Kaiser patented connections. This paper presents the analytical modeling, non-linear behavior and the results of the comparison studies in detail including obtained conclusions.

doi: $10.5829 /$ idosi.ije.2013.26.10a.03

\begin{tabular}{llll}
\hline NOMENCLATURE & & \\
\hline$M_{f}$ & Probable maximum moment at the face of the column (N-mm) & $H_{t}$ & Exterior height of bracket top (mm) \\
$A_{b}$ & Bolt nominal cross-sectional area $\left(\mathrm{mm}^{2}\right)$ & $H_{b}$ & Exterior height of bracket bottom (mm) \\
$F_{n t}$ & Nominal tensile strength of bolt from the AISC specification (mPa) & $t_{E P}$ & Thickness of bracket's end plat (mm) \\
$d_{e f f}$ & $\begin{array}{l}\text { Effective beam depth, calculated as the centroidal distance between } \\
\text { bolt groups in the upper and lower brackets (mm) }\end{array}$ & $t_{s}$ & Stiffener's thickness (mm) \\
$n_{c b}$ & $\begin{array}{l}\text { Number of column bolts } \\
\emptyset_{n}\end{array} \quad \begin{array}{l}\text { Resistance factor for non-ductile limit states } \\
\alpha\end{array} \quad \begin{array}{l}\text { Reduction factor, due to reduced effective depth of FSFN } \\
\text { connection, it is equal to 9/8 }\end{array}$ & $d_{h b}$ & Distance between stiffeners (mm) \\
$L$ & Length of bracket (mm) & $d_{v b 1}$ & Horizontal distance of bolts (mm) \\
$B$ & Width of bracket (mm) & $d_{v b 2}$ & row (mm) \\
$H$ & Total height of bracket (mm) & $L_{m w}$ & Vertical distance between the second and third bolt \\
rowm (m) & Length of middle slot (mm) \\
\end{tabular}

\section{INTRODUCTION}

In high seismic risk areas such as California and Japan, steel-framed buildings have been employed frequently because of their excellent performances in terms of

*Corresponding Author Email: Fr.Shahidi@yahoo.com (Farhad Shahidi) strength and ductility. Nonetheless, a large number of entirely unexpected severe brittle cracks of welded beam-to-column connections were found in the recent Northridge and Kobe earthquakes [1, 2]. The majority of the investigations showed that premature cracking in welded steel connections resulted from a combination of factors, such as high strain demands coupled with large inherent flaws and stress, overreliance on low-toughness 
materials, deficient field welding and insufficient quality control. In order to prevent such brittle fractures, both connection design and execution need to avoid the presence of notches, other possible stress concentration sources and excessively weak panel zones [3]. Several studies were conducted to improve the seismic performance of moment connections and a variety of connections were proposed. Tsai and Popov [4] pointed out that the use of an End-plate rib stiffener combined with stronger bolts could significantly improve the behavior of extended end-plate connections under large cyclic loading, which could then be designed to develop the full plastic moment capacity of the beam. They also noticed that the prying forces were reduced by the use of the end-plate rib stiffener. Seradj [5] has experimentally studied several end-plate connections under cyclic loading. He concluded that rigidity of endplate connections under cyclic loading depends on thickness of the end-plate and bolt diameter. It was also shown that using thinner end-plates and thicker bolts may lead to semi-rigid behavior. Swanson et al. [6] have numerically studied the behavior of T-stub flanges under monotonic loading. Two types of FE models were employed: A three dimensional T-stub model consisting of brick and wedge elements and several two dimensional T-stub flange models consisting of rectangular and triangular elements. They found that the pressure distributions between the T-stub flange and column flange are complex and are influenced by flange thickness and tension bolt location. They also found, that T-stub flange deformation models are sensitive to tension bolt pretension. The flange strength, however, is not greatly affected by the tension bolt pretension. Popov et al. [7, 8], have experimentally tested the behavior of T-Stub connections. They demonstrated that the use of 1 -in. (25.4-mm) bolts requires a greater distance between the bolt and the end of the fillet weld. Alternatively, it appears that the bolts can be omitted altogether. In addition, they stated that, the construction based on this design requires shims during erection, but with shims properly installed, the connection develops less residual strain than the welded one. Also, they found that the global behavior of the bolted connection with the T-stub is very close to that corresponding to a cover plate connection. The stem reinforces the connection and increases the maximum load-carrying capacity (moment capacity) and the degree of beam local buckling is relatively small. Gerami et al. [9], studied the behavior of T-stub and end-plate connections under cyclic loads using a nonlinear FEM. This study showed that the increase in vertical distance between the bolts and the beam flange produces hysteresis loops with more pinching, especially in $\mathrm{T}$ stub connections. The probability of failure mode change in T-stub connection is higher than that of endplate connection under cyclic loading due to the bolt arrangement change. Cyclic behaviors of T-stub and end-plate connections with stiffeners are somewhat close to the top-seat angle moment connections with stiffeners. In 1998, a group of researchers worked on bracket of connection at "Lehigh" university. Kasai et al. [10] have experimentally studied the cyclic behavior of a type of welded moment bracket connection similar to the top-seat angle connections with stiffeners. This type of connection has moment behavior. Then, a company called "ICF Kaiser Engineering" invented Kaiser bolted bracket (KBB) for moment connections. This bracket is made of cast high-strength steel. Blaney et al. [11] concluded that the addition of bolted brackets on both the top and bottom beam flanges was an effective method of strengthening the pre-Northridge moment connections typically occurring with the subject building and was able to force flexural yielding and plastic hinge formation into the beam. Adan et al. [12] have experimentally studied the behavior of bolted bracket connections. The result of this investigation showed that for a new construction the KBB connection is able to satisfy the criteria in appendix S of the AISC Seismic Provisions (AISC) for qualifying a connection to be used in a special moment frame.

The connection directs yielding and inelastic beam deformation away from the column face and outside the connected region. Shahidi et al. [13] have numerically studied the behavior of KBB moment connection. Twenty specimens were employed and nonlinear material characteristics and non-linear geometric behavior in the all specimens was used to predict the cyclic behavior of the connection. The results of finite element investigation of the seismic behavior of KBB connections showed that use of the tapered wedge shims intensify pinching effect in hysteresis curves and reduce pre-tension force in the column bolts. They also found that $\mathrm{W}$ - series seismic performance is lower than Bseries. In this study, non-linear finite element method is used to predict the behavior of new brackets (FSFN brackets). This brackets have the same seismic behavior as combination of T-Stub and KBB connections. The results showed that the seismic performance of new brackets is appropriate. Figure 1 shows a sample of FSFN bracket and KBB bracket.

\section{SCOPE OF THE STUDY}

This study is to evaluate the seismic performance of the new connection in comparison with $\mathrm{W}$-series of KBB connection under standard and near fault loading history based on AISC 341 and FEMA 355D. The specimens are evaluated by non-linear finite element method. To study the numerical models and to verify them against experimental results, the finite element software, ABAQUS ver.6.10 is used. 


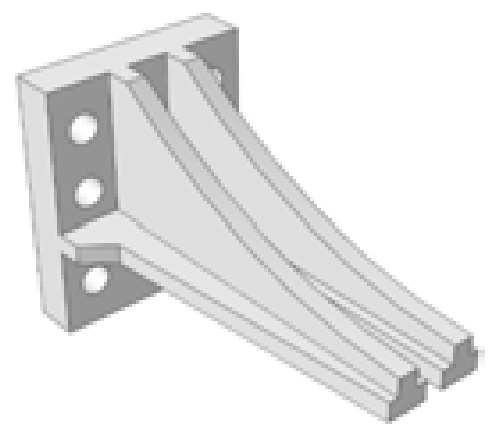

(a)

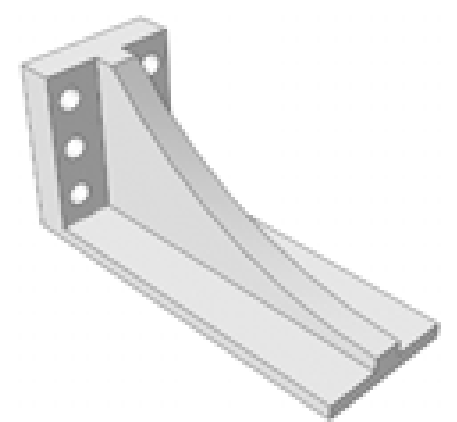

(b)

Figure 1. FSFN and KBB bracket moment resisting connections, (a) A type of FSFN bracket moment resisting connection, (b) A type of KBB bracket moment resisting connection.

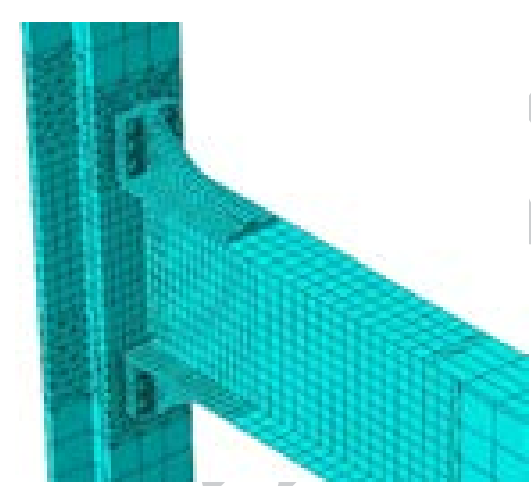

(a)

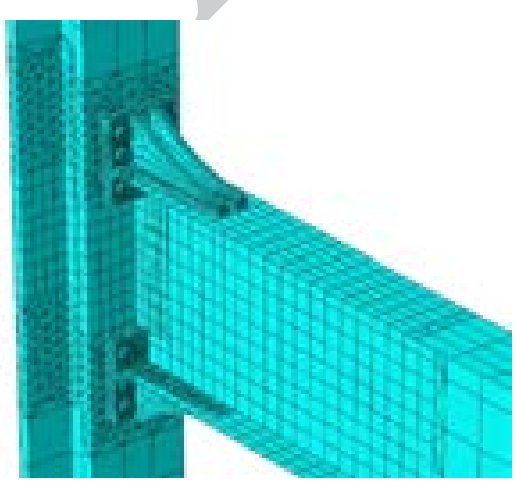

(b)

Figure 2. FE models, (a) FE model of KBB connection, (b) FE model of FSFN connection.

\section{NUMERICAL MODELS AND VERIFICATIONS}

The experimental specimen and FE models of connections were single-sided beam to column assemblies that are representative of exterior beam to column connections. In order to evaluate the accuracy of FE model, the FE results are compared with experimental results of HH-08 specimen tested by Scott M. Adan et al. [12]. In FE model, a cast high-strength steel bracket is fastened to each beam flange by weld and bolted to the column flange. To study on FE models, the finite element software, ABAQUS ver.6.10 is used. The bracket is welded to beam flange, so slippage between bracket and beam flange is negligible. Thus the slippage is ignored in weld FE modeling. For welds simulation, "Tie" constraint is used. The tie constraint allows fusing together two regions nodes even though the meshes created on the surfaces of the regions may be dissimilar. These constraints prevent slave nodes from separating or sliding relative to the master surface [14]. Column, bracket and bolt are modeled using 8-node solid element with reduced integral, C3D8R. This element has plasticity, creep, swelling stress stiffening, large deflection and large strain capabilities and allows orthotropic properties and also pressure [14]. The beam is modeled using 4-node shell element with reduced integral, S4R. Each shell node has six degrees of freedom, three translational and three rotational. The shell elements have plasticity, stress stiffening, large deflection, and large strain capabilities [14], Figure 2 shows the FE model. In FE models, brackets are fastened to each beam flange by "Tie constraint" which are bolted to the column flange by surface-to-surface contact interaction.

For applied contact stress, surface to surface element is used with regard to the effect of hard contact on the surfaces between the shank and bolt holes and that of the contact between of bracket and column flange. This option can consider the effect of contact stress between the surfaces without any integration of the bodies and their possibility of getting separated after the contact [14]. To determine the horizontal component of contact stress, Coulomb friction coefficient is assumed equal to 0.33 [15]. Based on AISC Load and Resistance Factor Design Specification code, steel surfaces are classified into three types: A, B and C surfaces. In this study, as the steel surface was unpainted and only cleaned through abrasion, so it would be classified as a class A surface [15]. In a class A surface, friction coefficient is 0.33, other researchers such as Popov et al. [8] have considered the friction coefficient equal to 0.33 for steel connections. Therefore, to consider the frictional forces, Coulomb's coefficient is assumed to be 0.33 , which yields the best results. For connected beam shear tab to column flange, used "Shell-to-solid coupling constraints" in the software. 
TABLE 1. Material properties used in all specimens and specimens to validate numerical and experimental results [12, 16]

\begin{tabular}{lcccc}
\hline Material & Application & Yeild Stress (MPa) & Ultimate Stress (MPa) & Ultimate Strain \\
\hline ASTM A572 Gr50 & Beam, Shear Tab & 366 & 462 & 0.25 \\
ASTM A572 Gr50 & Column & 321 & 453 & 0.25 \\
ASTM A148 Gr80/50 & Bracket & 510 & 710 & 0.22 \\
A490 & Bolt & 800 & 1050 & 0.18 \\
\hline
\end{tabular}

This surface-based option allows for a transition from shell element modeling to solid element modeling in a three-dimensional analysis [14]. The transfer of pretensioned force to bolts is defined in two steps described below:

In the first step, pre-tensioned force of the bolts is applied and in the second step, in addition to the continuity of pre-tensioned force of the bolts, loading is done as the applied displacement to end of beams. Material properties obtained from paper and experimental results of KBB connection, which have been carried out by Adan et al. [12, 16], are shown in Table 1. Experimental tests were performed under ATC 24 loading protocol. The loading protocol followed ATC-24 guidelines as shown in Figure 3 and is obtained from the experimental result. Stress-strain relation for beam material is represented using three-linear constitutive model and materials of other connection components were modeled as bilinear. Stress-strain curves of materials are shown in Figure 4. An isotropic multi-linear kinematic hardening rule with a von Mises yielding criterion is applied to simulate plastic deformations of the connection components. Popov et al. [8] used isotropic multi-linear kinematic hardening to investigate cyclic behavior of T-stub moment bolted connections. From Figure 5, it can be seen that similar to experimental specimen, in the FE model, the plastic hinge in the $\mathrm{HH}-08$ specimen is formed at $460 \mathrm{~mm}$ from the column face. Figure 5 shows the comparison between hysteresis loops of experimental specimen (HH-08) and FE model. It can be seen from Figures 5 and 6 that a generally good agreement is achieved between the finite element analysis results and the experimental ones for all specimens so that the maximum amount of error (infimum error) in all specimens is less than $5 \%$ which indicates the feasibility of modeling. In this paper, the mechanical properties, geometric characteristics and loading of all specimens were examined which were similar to experimental specimens. The boundary conditions of all specimens will be described in section 4 .

\section{BOUNDARY CONDITIONS AND LOADING}

Boundary conditions and positions of lateral bracing of all specimens are shown in Figure 7. To achieve the specified drifts, vertical displacements were imposed at the rigid plate of the beam tip in accordance with AISC 341 (for standard loading history) [17] and FEMA 355D (for near fault loading) [17-20].

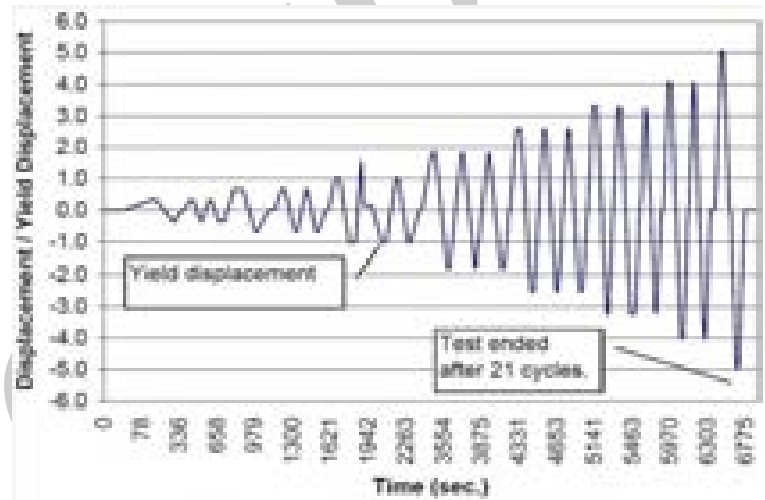

Figure 3. Time history of actuator displacements normalized to yield displacement. It is obtained from the experimental test, yield displacement is $50 \mathrm{~mm}$ (1 in) [16].

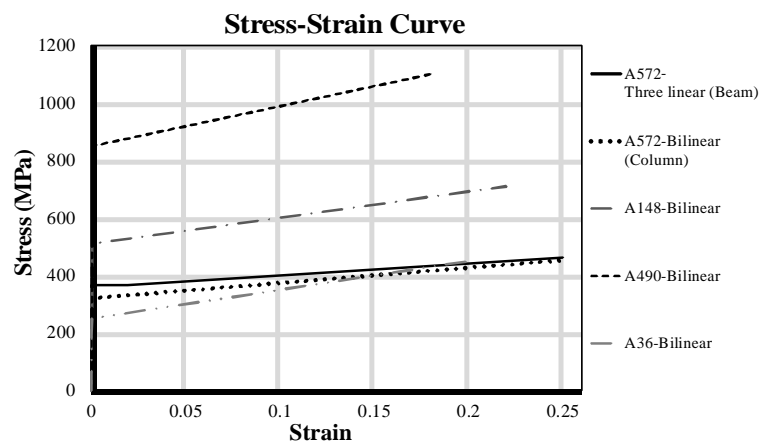

Figure 4. Stress-strain curves of the materials

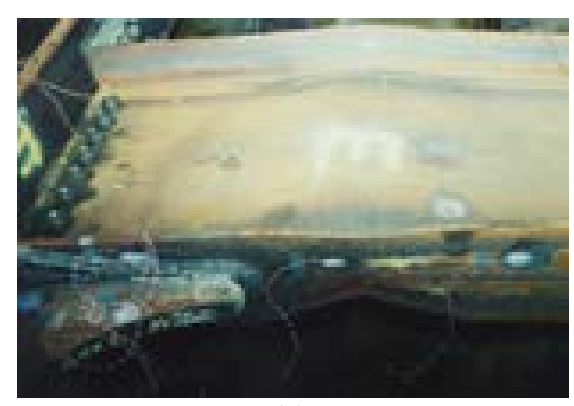

(a) 


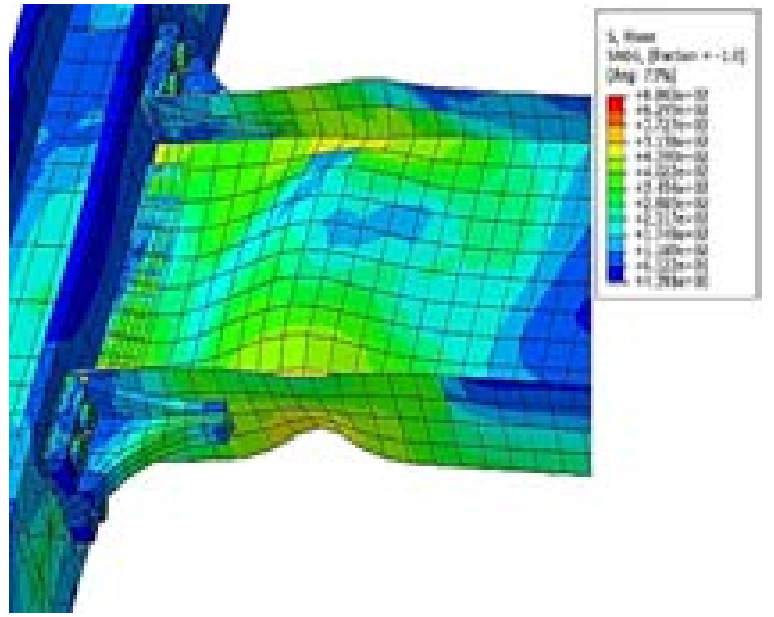

(b)

Figure 5. Deformation of experimental and numerical specimens at end of the test (0.056 rad), (a) prototype of $\mathrm{HH}$ 08 [12], (b) FE model of HH-08.

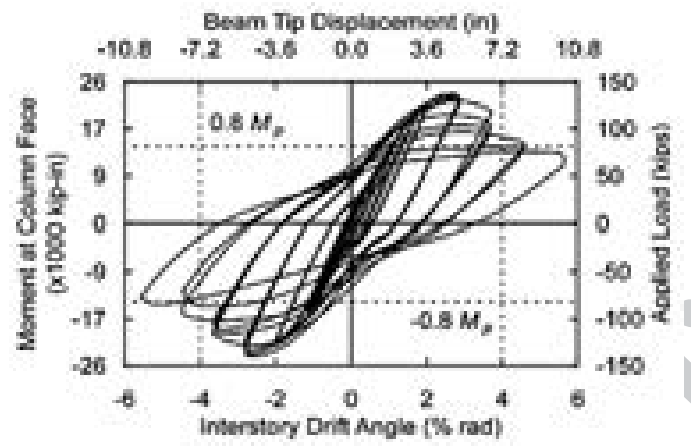

(a)

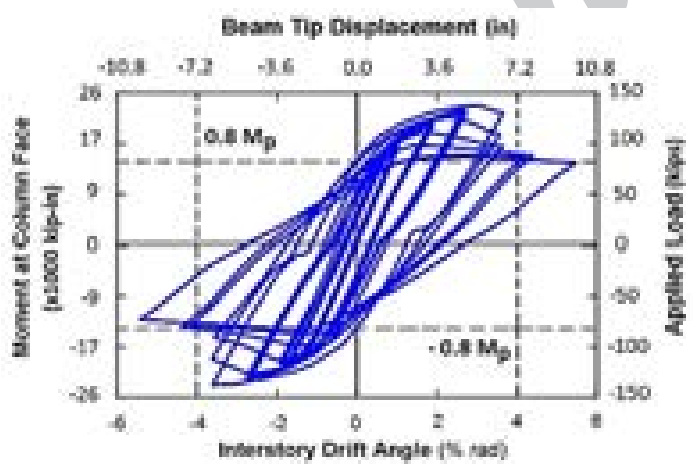

(b)

Figure 6. Hysteresis curves of KBB connection, (a) experimental hysteresis curve [12], (b) numerical hysteresis curve.

Figure 8 shows the loading protocols applied in free end of the beam. FEMA 355D divides loading protocol of steel connection into two types: Standard loading history and near fault loading history. In the first, FEMA standard loading protocol and AISC 341 loading protocol are the same, and their acceptance criteria are also similar. In this loading protocol, connection qualification primarily focuses on the level of plastic rotation achieved, the tendency for connections to experience strength degradation with increased deformation is also of concern. Strength degradation can increase rotation demands from $\mathrm{P}$ - effects and the likelihood of frame instability. In the absence of additional information, it is recommended that this degradation should not reduce flexural strength, measured at a drift angle of 0.04 rad., to less than $80 \%$ of the nominal flexural strength, $\mathrm{M}_{\mathrm{p}}$, calculated using the specified minimum yield stress, $F_{\mathrm{y}}$ [17]. Near fault loading history are mentioned in FEMA 355D and SAC. Near fault ground motions present a special problem. The response to them is often characterized by one very large excursion, followed by a large number of small cycles with large mean deformation amplitude. It is expected that the cumulative damage is controlled by the first large excursion, which corresponds to monotonic loading of the test specimen. However, the subsequent smaller cycles may lead to additional deterioration that needs to be evaluated. No specific attention has been paid to the characteristics of near fault response in the development of the standard loading history. The results to be obtained from the SAC near-fault response studies will be utilized to develop such a history. The behavior under such deformation histories cannot be deduced from the standard loading history and requires a special testing program [19, 20]. This loading history is developed specifically for performance evaluation at one specific level of response, representing the effect of near fault ground motions on SMRF behavior [20]. Near fault loading history has two required halves. In this study, the first half is repeated after the end of two required halves. The first half of the history examines performance for one loading direction, and the second half of the history examines performance for the opposite loading direction [20]. The second half of the history can serve as an acceptance test only if the first half of the history has not led to observable deterioration of strength for the opposite direction of loading [20]. Meanwhile, in the first step of loading, which is similar to the monotonic loading, cumulative damage should be controlled [19, 20]. The transfer of pre-tension force to bolts is defined in two steps. In first step, pre-tension force of the bolts is applied and in second step, in addition to the continuity of pre-tension force of the bolts, loading is done as the applied displacement to end of beams. Specifications and amount of bolts pre-tensioned force are obtained from RCSC 2009 [21]. For nominal bolts with diameters of 38 mm (1 1/2"), 32 mm (1 1/4") and 28 mm (1 1/8"), pre-tensioned forces are $660 \mathrm{kN}$ (148 kips), $632 \mathrm{kN}$ (142 kips) and 356 kN (80 kips) respectively. 


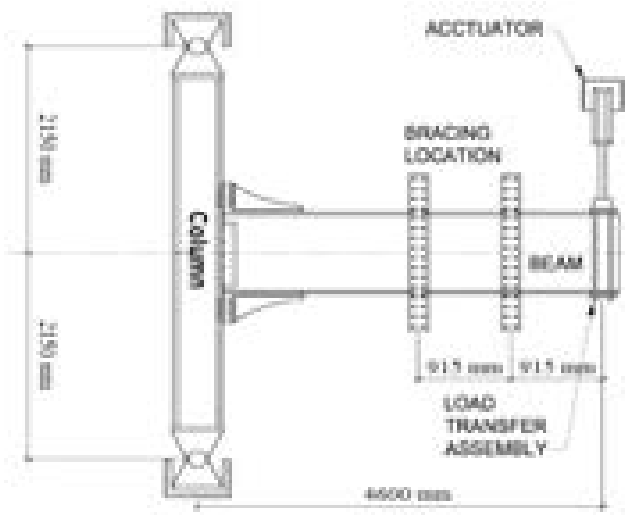

Figure 7. View of the test assembly and specimens boundary conditions [12].

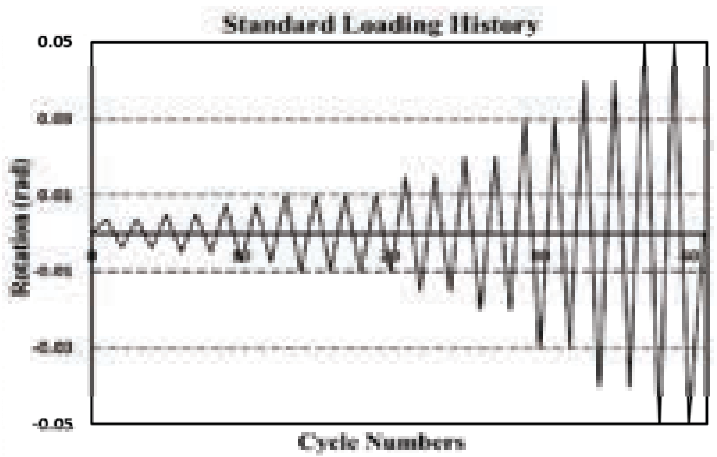

(a)

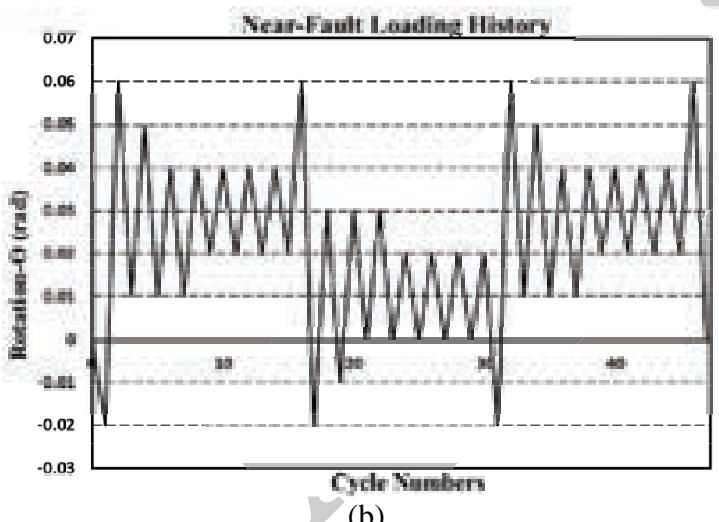

Figure 8. Loading protocol of the specimens, (a) Standard loading history, (b) Near-fault loading history.

\section{NUMERICAL RESULTS}

This study evaluates seismic performance of the new innovative connection (FSFN bracket connection) in comparison with Kaiser welded series connection in both far and near fault zones. For this study, two group of specimens were studied, the specimens which were studied under the standard loading history as "Group 1" and other specimens studied under the near-fault loading history as "Group 2". Here, W-sections were used in all the beams and columns. In addition, columnto-beam ratio in all the specimens is considered accordance with AISC 341 [17]. In all the specimens, the columns did not need continuity plate and doubler web plate according to AISC 358. Also, in all the columns, panel zones were of strong type [22, 23]. Specifications of the bolts and criteria of their pretension were determined according to RCSC [21]. Kaiser connection is a cast steel connection and ICF Kaiser engineering company holds its patent. FSFN connection is a connection similar to Kaiser connection which is derived from T-Stub connection. It is supposed that this connection is made of high-strength steel, ASTM-A148. The connection has smaller dimensions and external height compared with Kaiser connection, especially in deep beams. In KBB connection, maximum permissible beam section depth is $84 \mathrm{~cm}$ (W33) [23]. This limitation is due to inadequacy of weld length connecting bracket to beam flange and high stress concentration in bracket stiffeners for the beams with depths exceeding $84 \mathrm{~cm}$ (W33); whereas, FSFN connection can be used for the beams with depths up to $100 \mathrm{~cm}$ (W40). This is performed by creating a middle slot to provide a longer weld length. Also, two stiffeners are used to distribute stress more evenly. Figure 9 shows stress distribution in both types of connections for a similar beam and column. These connections are evaluated up to the range of deep beams. Table 2 shows the specifications of all the specimens. This connection is derived from the T-Stub connection. Studies of Gerami et al. [9] showed that T-Stub connection is sensitive to horizontal distance of bolts, and also change in the horizontal distance of bolts leads to change of failure mode and location of the plastic hinge. The FSFN connection does not have this problem; therefore, this problem can be resolved in design. The usable range of beams, in FSFN connection, can be found in Table 3. Due to having smaller external dimensions, especially in deep beams, this connection leads to decreasing thickness of false ceiling or removing it in architectural design. Appendix 1 shows the design specifications and geometrical details of the brackets. According to "AISC Load and Resistance Factor Design Specification", Coulomb's friction coefficient is considered as 0.33 in all the specimens for all the surfaces in contact. The beam plastic hinge in FSFN connection is formed after the brackets. The distance between the plastic hinge and column face is equal to the length of bracket. Figure 10 shows formation of the plastic hinge at the last step of loading for some specimens. In addition, Equivalent Plastic Strain criteria (PEEQ) and Von Mises stress criteria are used to detect yielding and location of plastic hinge. Under standard load history, this connection has far Fault seismic performance similar to the Kaiser connection; Figure 11 shows standard hysteresis curves for all the specimens. 
TABLE 2. Specifications of numerical specimens*

\begin{tabular}{|c|c|c|c|c|c|c|c|c|}
\hline Group & Name & Bracket & Column & Beam & Load type & Beam section depth (mm) & $\mathrm{Z}_{\mathrm{b}} \cdot \mathrm{F}_{\mathrm{Yb}}(\mathrm{kN} . \mathrm{m})$ & $\frac{\sum \mathrm{M}_{\mathrm{Pc}}}{\sum \mathrm{M}_{\mathrm{Pb}}}>\mathbf{1}$ \\
\hline \multirow{16}{*}{$\begin{array}{l}\overrightarrow{0} \\
\text { है }\end{array}$} & SL-FSFN-01 & FSFN-A & W14x283 & W40x149 & Standard & 971 & 3587 & 1.11 \\
\hline & SL-FSFN-02 & FSFN-A & W14x283 & W36x135 & Standard & 904 & 3053 & 1.31 \\
\hline & SL-FSFN-03 & FSFN-A & W14x283 & W33x141 & Standard & 846 & 3083 & 1.29 \\
\hline & SL-FSFN-04 & FSFN-A & W14x283 & W30x124 & Standard & 767 & 2447 & 1.60 \\
\hline & SL-FSFN-05 & FSFN-B & W14x233 & W30x108 & Standard & 757 & 2075 & 1.56 \\
\hline & SL-FSFN-06 & FSFN-B & W14x233 & W27x114 & Standard & 693 & 2057 & 1.59 \\
\hline & SL-FSFN-07 & FSFN-B & W14x233 & W21x93 & Standard & 549 & 1325 & 2.47 \\
\hline & SL-FSFN-08 & FSFN-B & W14x233 & W18x106 & Standard & 475 & 1379 & 2.40 \\
\hline & SL-FSFN-09 & FSFN-C & W14x233 & W21x93 & Standard & 549 & 1325 & 2.39 \\
\hline & SL-FSFN-10 & FSFN-C & W14x176 & W21x57 & Standard & 536 & 774 & 3.32 \\
\hline & SL-FSFN-11 & FSFN-C & W14x176 & W18x60 & Standard & 462 & 738 & 3.48 \\
\hline & SL-FSFN-12 & FSFN-C & W14x176 & W16x57 & Standard & 417 & 630 & 4.07 \\
\hline & SL-KBB-13 & W1.0 & W14x283 & W33x141 & Standard & 846 & 3083 & 1.29 \\
\hline & SL-KBB-14 & W2.1 & W14x233 & W30x108 & Standard & 757 & 2075 & 1.56 \\
\hline & SL-KBB-15 & W2.1 & W14x233 & W27x114 & Standard & 693 & 2057 & 1.59 \\
\hline & SL-KBB-16 & W3.1 & W14x176 & W21x57 & Standard & 536 & 774 & 3.32 \\
\hline \multirow{16}{*}{ 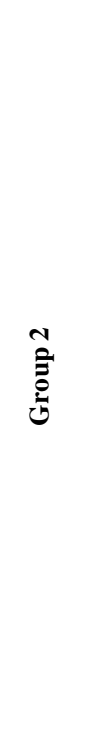 } & NFL-FSFN-01 & FSFN-A & W14x283 & W40x149 & Near-Fault & 971 & 3587 & 1.11 \\
\hline & NFL-FSFN-02 & FSFN-A & W14x283 & W36x135 & Near-Fault & 904 & 3053 & 1.31 \\
\hline & NFL-FSFN-03 & FSFN-A & W14x283 & W33x141 & Near-Fault & 846 & 3083 & 1.29 \\
\hline & NFL-FSFN-04 & FSFN-A & W14x283 & W30x124 & Near-Fault & 767 & 2447 & 1.60 \\
\hline & NFL-FSFN-05 & FSFN-B & W14x233 & W30x108 & Near-Fault & 757 & 2075 & 1.56 \\
\hline & NFL-FSFN-06 & FSFN-B & W14x233 & W27x114 & Near-Fault & 693 & 2057 & 1.59 \\
\hline & NFL-FSFN-07 & FSFN-B & W14x233 & W21x93 & Near-Fault & 549 & 1325 & 2.47 \\
\hline & NFL-FSFN-08 & FSFN-B & W14x233 & W18x106 & Near-Fault & 475 & 1379 & 2.40 \\
\hline & NFL-FSFN-09 & FSFN-C & W14x233 & W21x93 & Near-Fault & 549 & 1325 & 2.39 \\
\hline & NFL-FSFN-10 & FSFN-C & W14x176 & W21x57 & Near-Fault & 536 & 774 & 3.32 \\
\hline & NFL-FSFN-11 & FSFN-C & W14x176 & W18x60 & Near-Fault & 462 & 738 & 3.48 \\
\hline & NFL-FSFN-12 & FSFN-C & W14x176 & W16x57 & Near-Fault & 417 & 630 & 4.07 \\
\hline & NFL-KBB-13 & W1.0 & W14x283 & W33x141 & Near-Fault & 846 & 3083 & 1.29 \\
\hline & NFL-KBB-14 & W2.1 & W14x233 & W30x108 & Near-Fault & 757 & 2075 & 1.56 \\
\hline & NFL-KBB-15 & W2.1 & W14x233 & W27x114 & Near-Fault & 693 & 2057 & 1.59 \\
\hline & NFL-KBB-16 & W3.1 & W14x176 & W21x57 & Near-Fault & 536 & 774 & 3.32 \\
\hline
\end{tabular}

*For all specimens, friction coefficient is 0.33 .

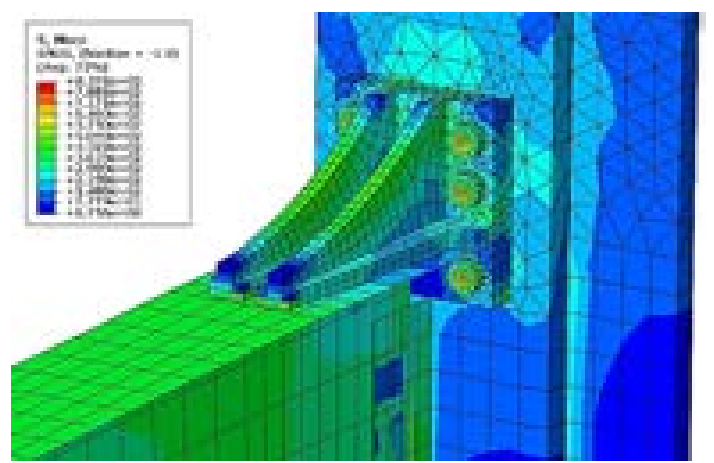

(a)

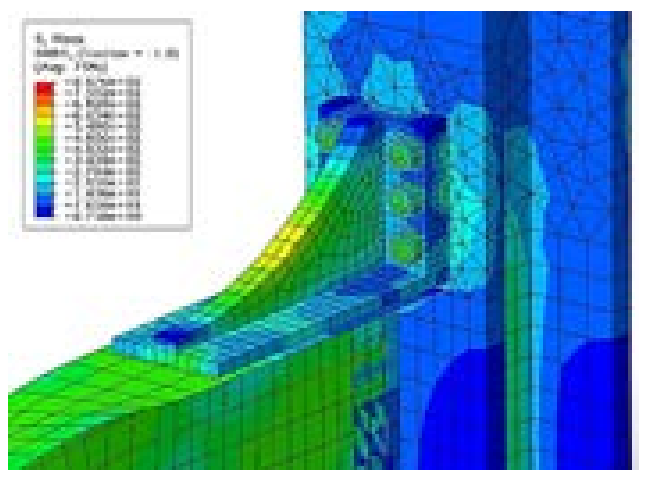

(b)

Figure 9. Stress distribution in brackets, (a) FSFN bracket, (b) KBB bracket 


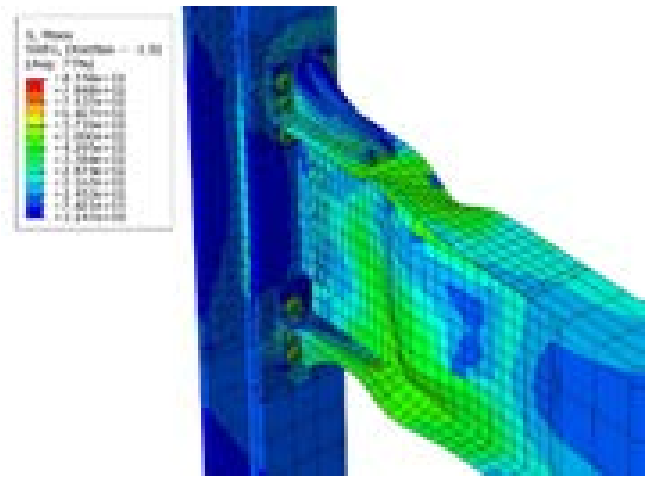

(a)

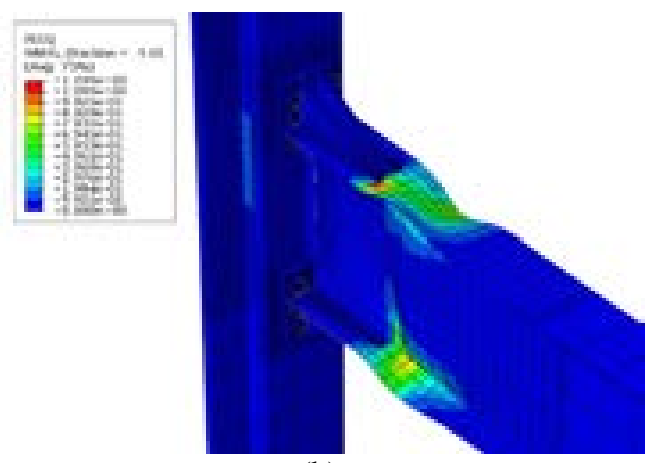

(b)
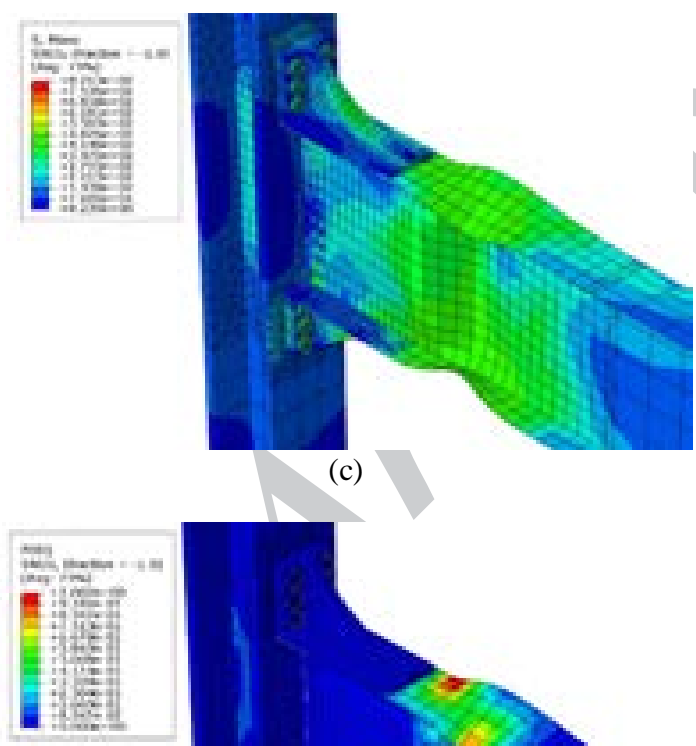

(c)

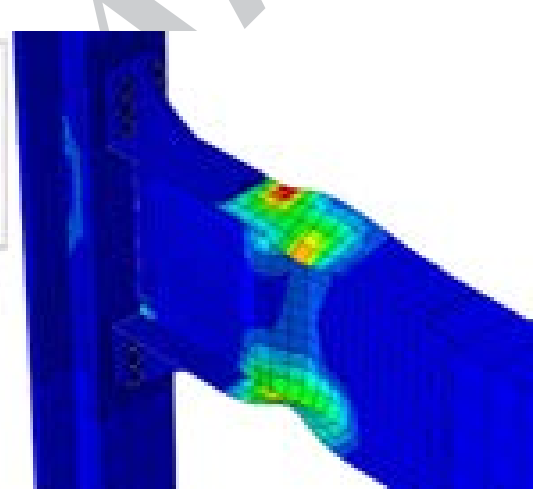

(d)

Figure 10. Plastic hinge location in some of specimens, (a, b) Von Mises and PEEQ criteria are used to detect yielding and location of plastic hinge in FSFN connections, (c, d) Von Mises and PEEQ criteria are used to detect yielding and location of plastic hinge in KBB connections.
TABLE 3. Range of the usable beams, in FSFN connection.

\begin{tabular}{lll}
\hline Bracket type & Beams range & $\begin{array}{l}\text { Plastic moment } \\
\text { range (kN.m) }\end{array}$ \\
\hline FSFN-A & W30x108 to W40x149 & $2000-3600$ \\
FSFN-B & W21x93 to W30x108 & $1300-2000$ \\
FSFN-C & $<$ W21x93 & $<1300$ \\
\hline
\end{tabular}

Obviously, the standard hysteresis of FSFN connection in all specimens satisfies rotations above 0.04 radians perfectly and this connection would be able to satisfy more than $80 \%$ of the computational plastic moment. Therefore, it can be considered as an appropriate connection for special moment frame. In deep beams, due to the reduction of bracket height, drop in pretension force of column bolts in this type of connection is more than Kaiser Brackets; Figure 12 shows these drops in the column bolts. Consequently, the formula of AISC 358 in order to satisfy the column bolt tensile strength of Kaiser connection for the FSFN connection can be modified as Equation (1). Original equations of AISC 358 are shown in Equations (2) and (3) [23]. Equation (1) is combination of Equations (2) and (3), which is multiplied in $\alpha$ coefficient. It is obtained from the numerical analysis.

$\frac{\alpha \cdot M_{f}}{\emptyset_{n} \cdot n_{c b} \cdot F_{n t} \cdot A_{b} \cdot d_{e f f}} \leq 1$

$r_{u t} \leq \emptyset_{n} . F_{n t} . A_{b}$

$r_{u t}=\frac{M_{f}}{d_{e f f} \cdot n_{c b}}$

Due to the depth reduction of the centroidal distance between bolt groups in the upper and lower brackets as compared with Kaiser connection, drop in pre-tension force of column bolts exceeds that of Kaiser connection. This is due to the decrease of beam effective depth that increased prying force in the column bolts. Parameter $\alpha$ is considered for this reduction. It is obtained from the finite element analysis. Other design formulas are similar to KBB connection. The main difference is that length of weld and such specifications should be considered with respect to the FSFN brackets. Appendix 1 shows the design proportions and geometrical details of the brackets. This connection has an appropriate near fault performance. FSFN connection has less strength deterioration and high energy dissipation in both far and near fault zones. According to SAC loading protocol $[19,20]$, no specific attention has been paid to the characteristics of near fault response in the development of the standard loading history.

A separate loading history that accounts for near fault effects needs to be developed. The results to be obtained from the SAC near fault response studies will be utilized to develop such a history. For deep beams, 
length of FSFN bracket is shorter than Kaiser bracket. Therefore, in order to ensure the proper weld length, in FSFN bracket middle slot weld is created. It makes longer weld length compared with KBB brackets. Middle slot can be filled by weld in order to supply the longer weld length. In addition, with respect to the middle slot weld and the use of two stiffeners, the brackets of this connection can be applied in the beams deeper than the Kaiser connection. As the FSFN brackets external height is less in deep beams, therefore, FSFN brackets are more capable to hide in architectural elements and flooring compared with the bracket of Kaiser connection. FSFN bracket is made of cast high- strength steel, and due to being factory-made, it has high speed execution and high quality. In these brackets, by eliminating worksite fillet weld in the new building process, the quality increases. FSFN bracket also can be used for rehabilitation in connections of old steel structures. It increases speed of execution and the quality. FSFN bracket provides reliable connection behavior in the earthquake. Finally, this connection is evaluated as a suitable connection for special moment frame in both near and far fault zones. Therefore, it can be considered as an appropriate alternative to the Kaiser patented connections.
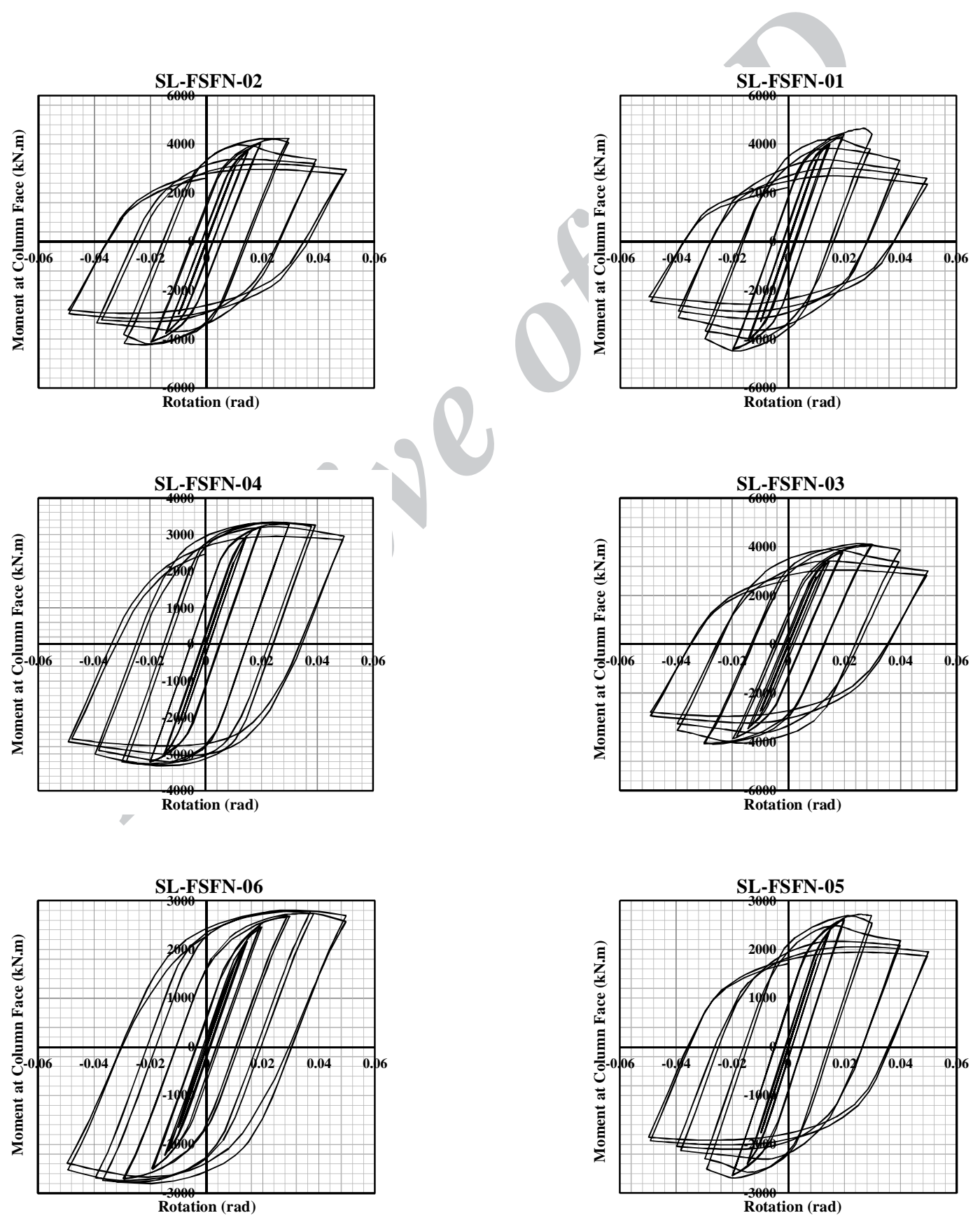

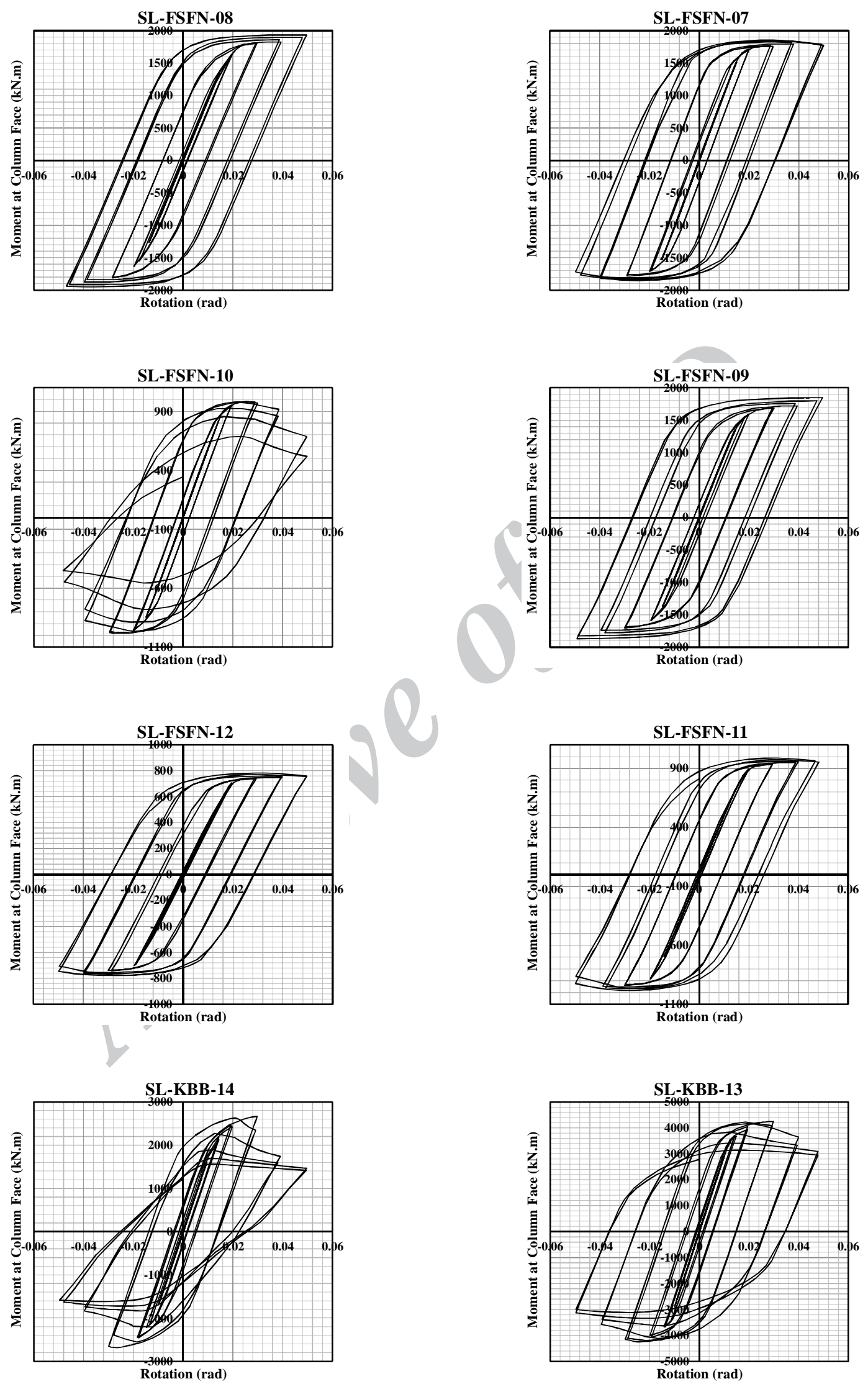

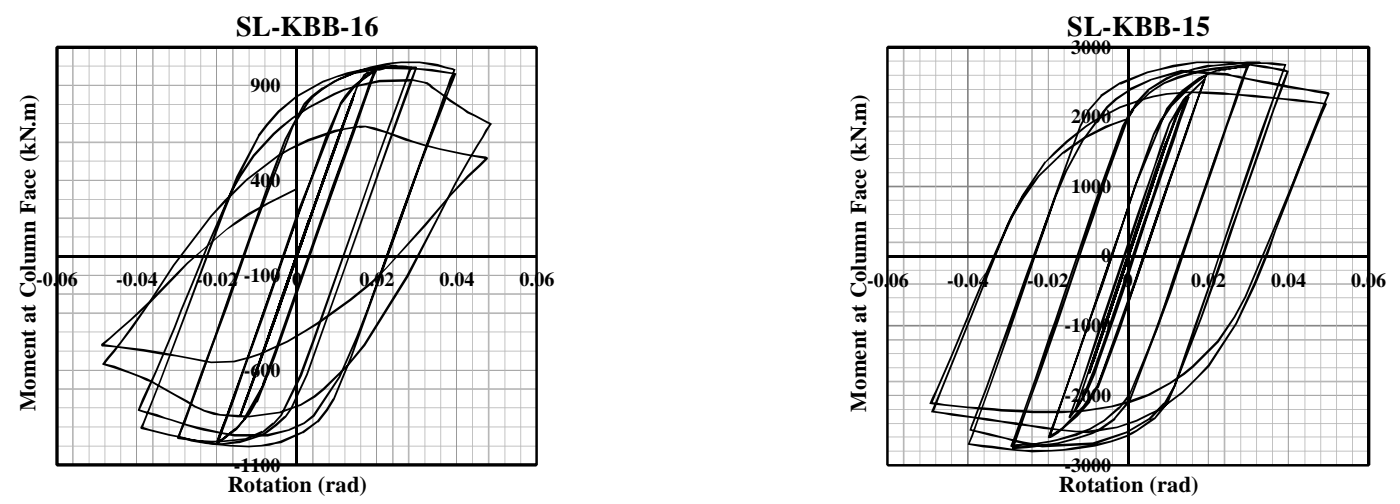

Figure 11. Standard hysteresis curves of Group 1.
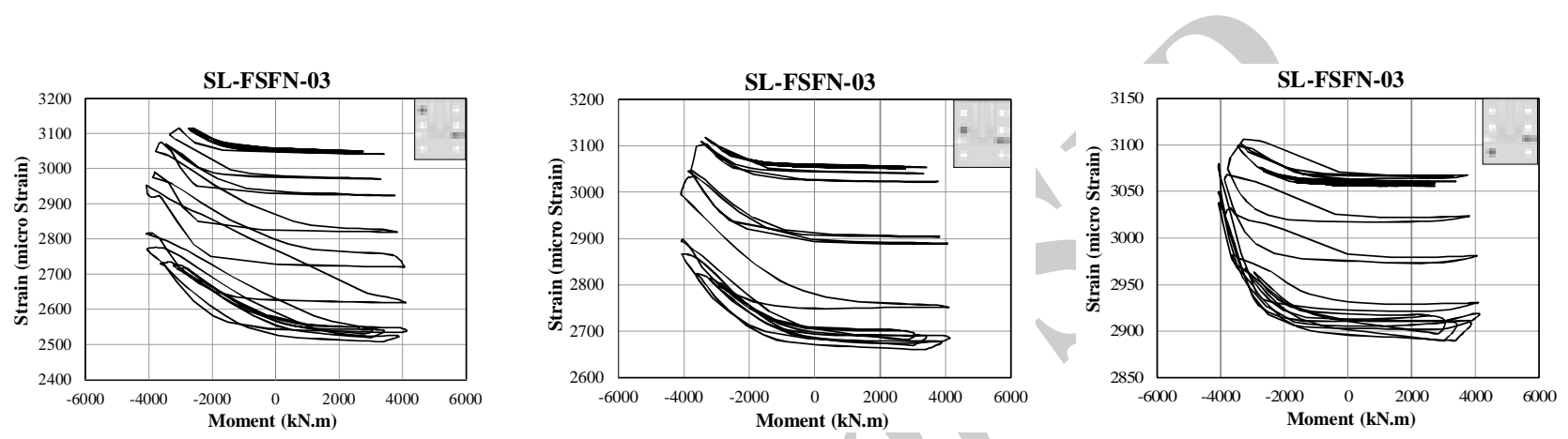

(a)
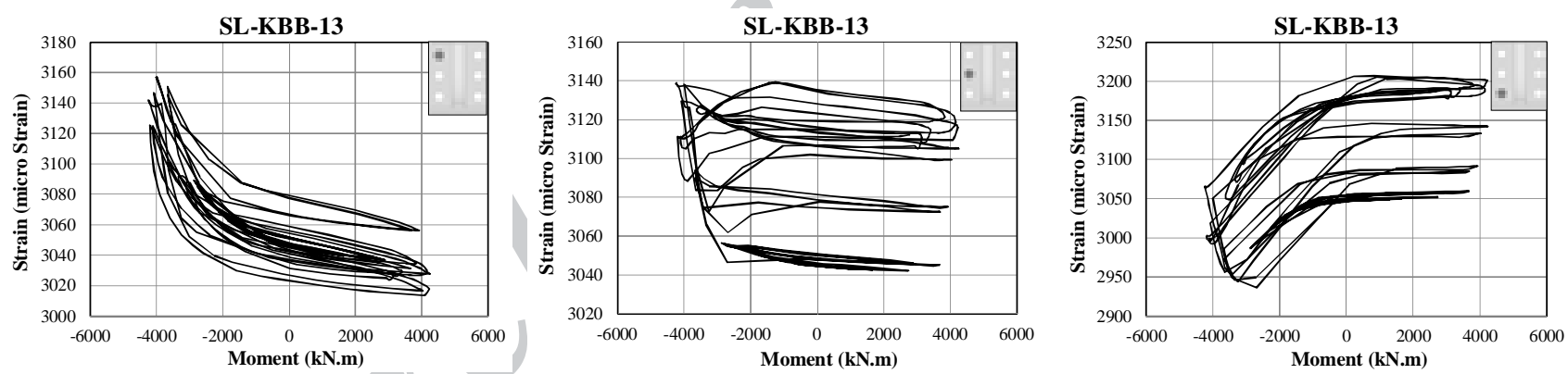

Figure 12. Drop in pre-tension force of column bolts in deep beams, (a) Moment-Strain curve for SL-FSFN-03, (b) Moment-Strain curve for SL-KBB-13.
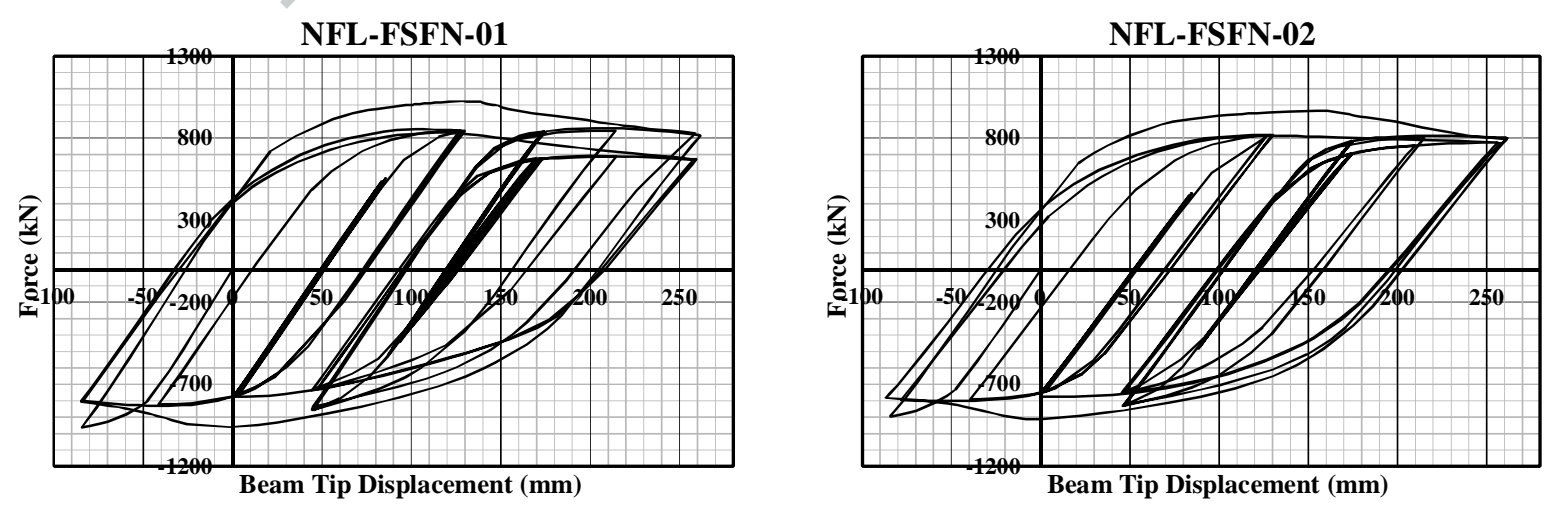

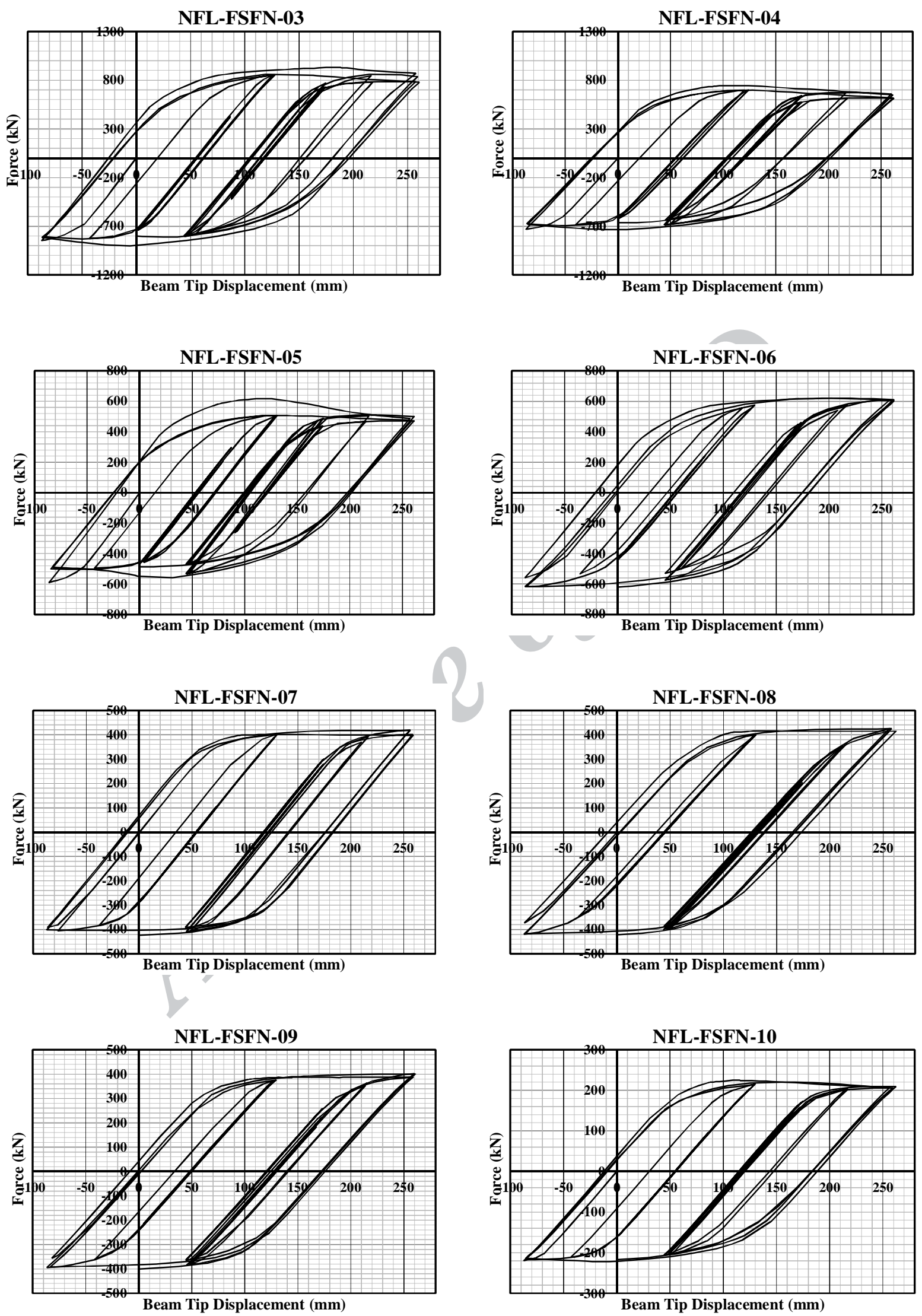

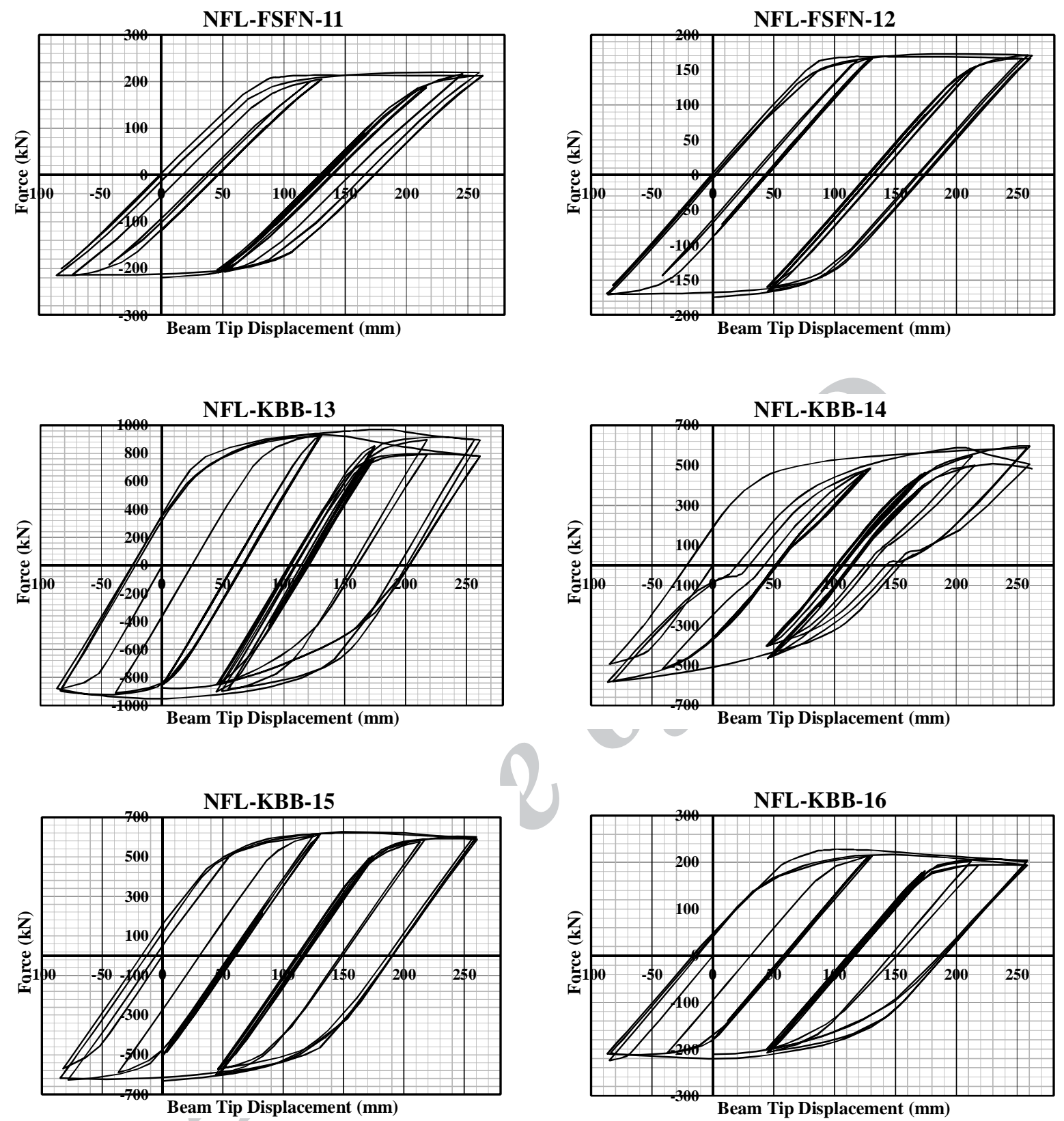

Figure 13. Near-fault hysteresis curves of Group 2.

\section{CONCLUSION}

In this study the seismic behavior of a new moment resisting connection, FSFN, was examined under standard and near-fault load histories that contain the following results:

Advantages of FSFN Bracket Connection:

* FSFN bracket connection has a seismic performance similar to the $\mathrm{W}$-series of KBB connection.
* FSFN bracket connection is an appropriate connection for the special moment frame in both far and near fault zones.

* FSFN bracket connection has an appropriate seismic performance in the beams with the maximal depth of $100 \mathrm{~cm}$ (W40), whereas maximum usable beam in a Kaiser connection is $84 \mathrm{~cm}$ (W33).

* In deep beams, the external height of the FSFN connection is less than KBB connection, which leads to further saving in materials, and this also leads to the 
decrease of flooring thickness and architectural elements to cover that.

* The length of FSFN bracket in deep beams is less than the Kaiser bracket. This leads to the increase in the rigidity of the bracket and suitable use of plastic moment capacity of deep beams.

* FSFN bracket is made of cast high-strength steel, ASTM-A148, and it is factory-made connection. Therefore, FSFN bracket assists to eliminate welding operation in workshop and increase the speed and quality of execution.

Disadvantages of FSFN Bracket Connection:

* Due to the depth reduction of the centroidal distance between bolt groups in the upper and lower brackets as compared with Kaiser connection, drop in pre-tension force of column bolts exceeds that of Kaiser connection. This is due to the decrease of beam effective depth that increased prying force in the column bolts.

* In the beams with short section depth, numbers of bolts in FSFN bracket are more than the KBB bracket.

Finally, seismic performance of FSFN bracket connection is evaluated positively. It can be used as an appropriate connection for the special moment resisting frame in structural systems.

\section{REFERENCES}

1. Bertero, V. V., Anderson, J. C. and Krawinkler, H., "Performance of steel building structures during the northridge earthquake", Earthquake Engineering Research Center, University of California, (1994).

2. Kuwamura, H., "Fracture of steel during an earthquake - stateof-the-art in japan", Engineering Structures, Vol. 20, No. 4, (1998), 310-322.

3. Bursi, O. S., Ferrario, F. and Fontanari, V., "Non-linear analysis of the low-cycle fracture behaviour of isolated tee stub connections", Computers \& Structures, Vol. 80, No. 27, (2002), 2333-2360.

4. Tsai, K.-C. and Popov, E. P., "Cyclic behavior of end-plate moment connections", Journal of Structural Engineering, Vol. 116, No. 11, (1990), 2917-2930.

5. H., S., Ductile end-plate connections utilizing plate yielding, in School of Civil Engineering and Environmental Science., University of Oklahoma: Norman. Oklahoma. (1997)
6. Swanson, J. A., Kokan, D. S. and Leon, R. T., "Advanced finite element modeling of bolted t-stub connection components", Journal of Constructional Steel Research, Vol. 58, No. 5, (2002), 1015-1031.

7. Popov, E. P. and Takhirov, S. M., "Bolted large seismic steel beam-to-column connections part 1: Experimental study", Engineering Structures, Vol. 24, No. 12, (2002), 1523-1534.

8. Takhirov, S. and Popov, E. P., "Bolted large seismic steel beamto-column connections part 2: Numerical nonlinear analysis", Engineering Structures, Vol. 24, No. 12, (2002), 1535-1545.

9. Gerami, M., Saberi, H., Saberi, V. and Saedi Daryan, A., "Cyclic behavior of bolted connections with different arrangement of bolts", Journal of Constructional Steel Research, Vol. 67, No. 4, (2011), 690-705.

10. Kasai, K., Hodgson, I. and Bleiman, D., "Rigid-bolted repair method for damaged moment connections", Engineering Structures, Vol. 20, No. 4, (1998), 521-532.

11. Blaney, C., Uang, C.-M., Kim, D.-W., Sim, H.-B. and Adan, S. M., "Cyclic testing and analysis of retrofitted pre-northridge steel moment connections using bolted brackets", SEAOC 2010 Convention Proceedings, (2010).

12. Adan, S. M. and Gibb, W., "Experimental evaluation of kaiser bolted bracket steel moment-resisting connections", Engineering journal, Vol. 46, No. 3, (2009), 181-194.

13. Shahidi, F., Nateghi-A, F. and Razzaghi, M., "Influential factor in improving the seismic performance of the kaiser bolted bracket moment connection", International Journal of Engineering-Transactions B: Applications, Vol. 26, No. 2, (2012), 163-170

14. Hibbitt, D., Karlsson, B. and Sorensen, P., "Abaqus/standard user's manual, version 6. 7, abaqus", Inc., Pawtucket, RI, (2007).

15. LRFD, A., "Manual of steel construction, load and resistance factor design" Chicago: American Institute of Steel Construction. (1994)

16. Adan, S. M., "Test report 98-05-specimen hh-08", ICF Kaiser Engineers, (1998).

17. Construction, A. I. o. S., "Seismic provisions for structural steel buildings", American Institute of Steel Construction, (2002).

18. Roeder, C. W. and Venture, S. J., "State of the art report on connection performance", SAC Joint Venture, (2000).

19. Venture, S. J., "Protocol for fabrication, inspection, testing, and documentation of beam-column connection tests and other experimental specimens", Rep. No. SAC/BD-97, Vol. 2, (1997).

20. Krawinkler, H., Gupta, A., Medina, R. and Luco, N., "Development of loading histories for testing of steel beam-tocolumn assemblies", Stanford University, (2000).

21. RCSC, "Specification for structural joints using high-strength bolts", Research Council on Structural Connections., (2009).

22. Cao, W.-G., Zhai, Y.-C., Wang, J.-Y. and Zhang, Y.-J., "Specification for structural steel buildings", Zhongguo Gonglu Xuebao(China Journal of Highway and Transport), Vol. 25, No. 2, (2012), 90-99.

23. ANSI, A., "Aisc 358-05 prequalified connections for special and intermediate steel moment frames for seismic applications", American Institute of Steel Construction Inc., Chicago, (2005). 


\title{
Non-linear Behavior of New (FSFN) Moment Resisting Connections in Comparison to the Existing KBB Connections in Steel Frames
}

\author{
F. Shahidia, F. Nateghi-Alahi' ${ }^{b}$ F. Shahidic
}

a Department of Civil Engineering and Surveying, Islamic Azad University of Qazvin, Qazvin, Iran
b International Institute of Earthquake Engineering and Seismology of Tehran, Tehran, Iran
c Department of Civil Engineering, Islamic Azad University of Takestan, Qazvin, Iran

$P A P E R \quad I N F O$

جكيده

Paper history:

Received 22 January 2013

Received in revised form 17 April 2013

Accepted 16 May 2013

\section{Keywords:}

FSFN Brackets

Non-linear Numerical Analysis

Standard Load History

Near-fault Load History

KBB Brackets

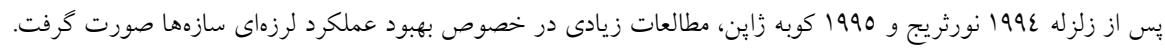

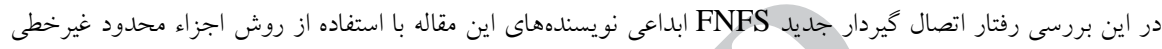

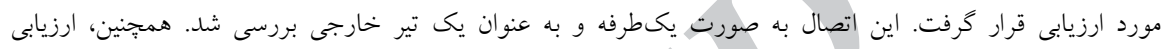

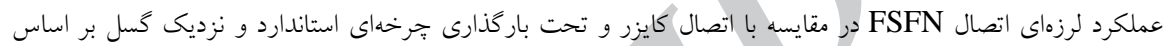

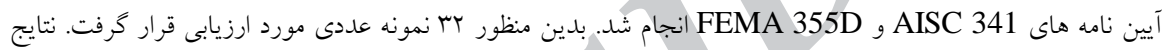

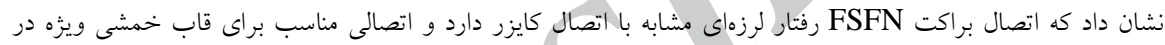

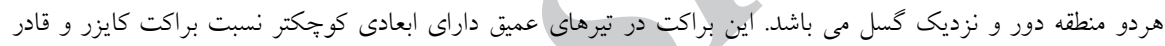

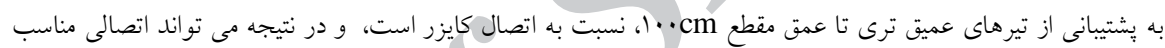

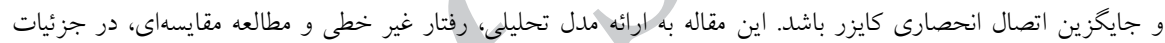
نتايج بهدست آمده مى يردازد. 


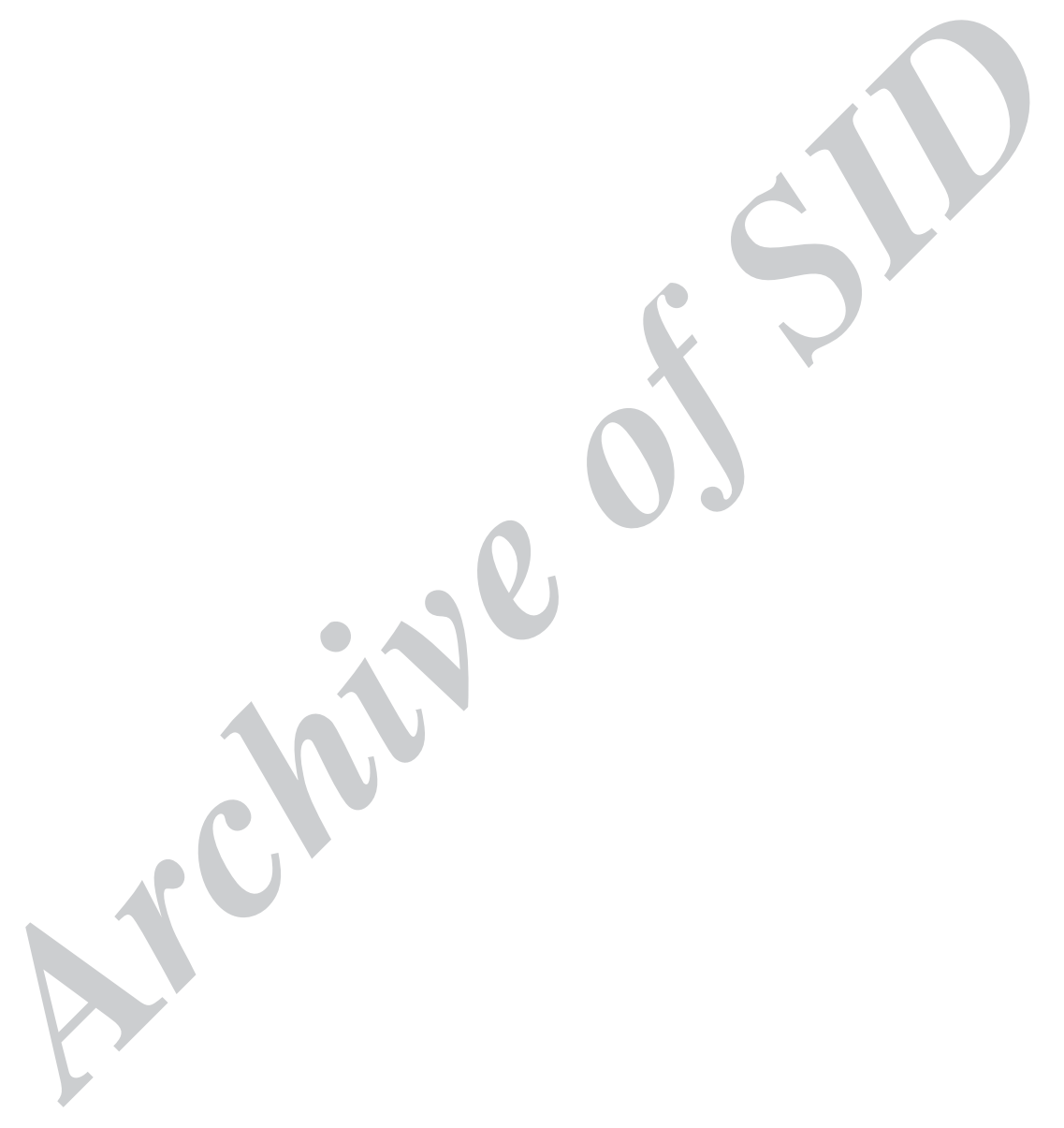




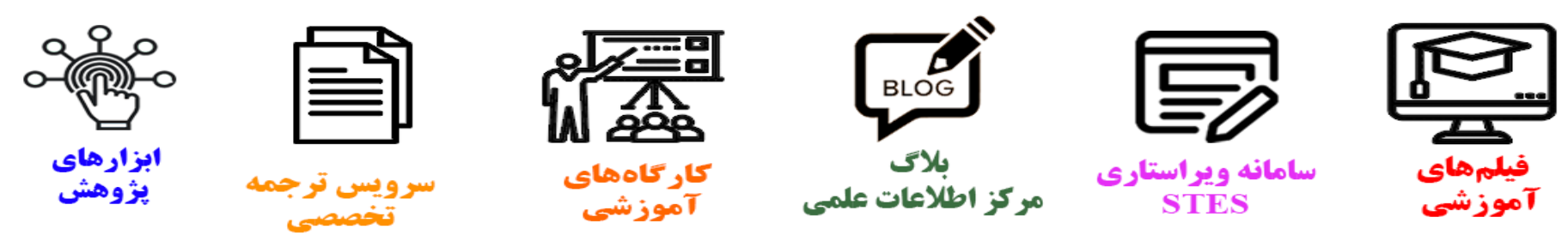

\section{(c)}

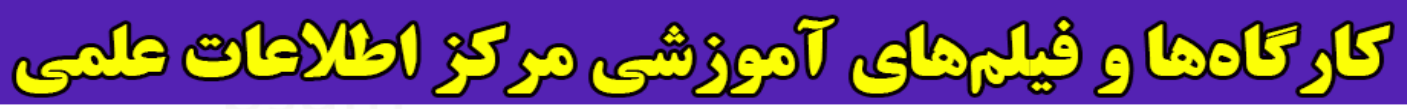
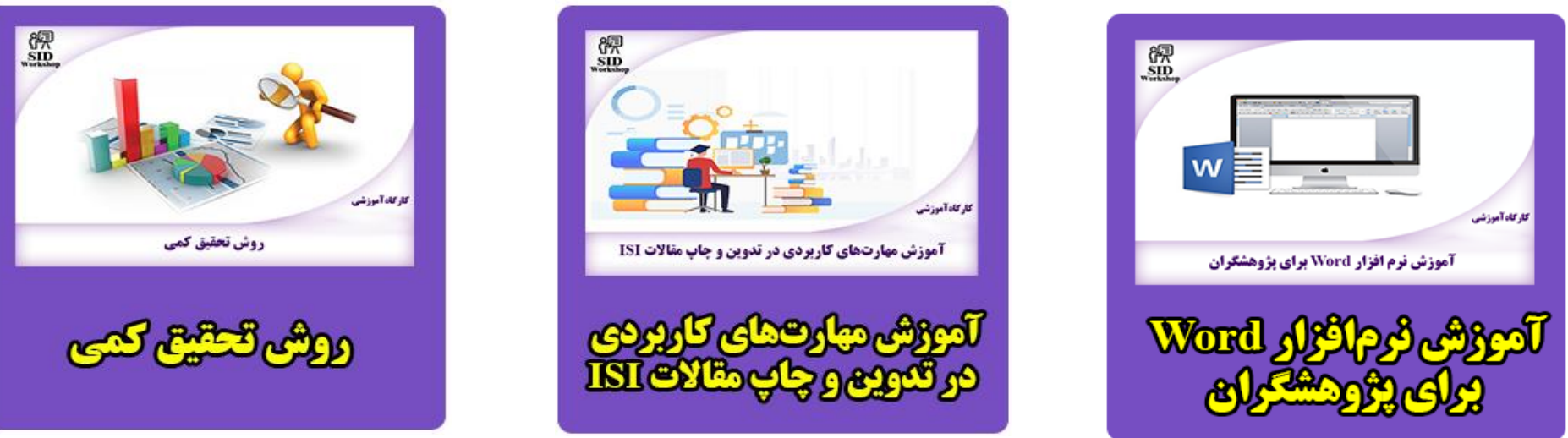